\title{
sciendo
}

DOI 10.2478/sbe-2019-0039

SBE no. 14(3) 2019

\section{GENDER AND OVERCONFIDENCE IN THE KAUFFMAN FIRM SURVEY}

\section{BAEK YOUNG}

Huizenga College of Business, Nova Southeastern University, USA

NEYMOTIN FLORENCE

Huizenga College of Business, Nova Southeastern University, USA

\begin{abstract}
:
While an emerging line of research has begun to examine how firm survival correlates with the psychological trait of overconfidence, almost none of this work looks at how this relationship is mediated or modified by the minority status of the individual within the area of entrepreneurship. We employ a proportional hazard survival model and analyze the Kauffman Firm Survey (KFS) of entrepreneurs during the period of 2004-2012. We find that, while overconfidence relates to firm survival, it is more strongly related to survival for female than for male entrepreneurs. Our analysis is unique in examining the trait of overconfidence for small firm survival, and it is the first that we know of to stratify the effects of this overconfidence by gender. The present work has implications for possible methods and strategies to promote the entrepreneurship of individuals from underrepresented groups, with an eye towards owner-overconfidence helping female-led firms to survive the first few years of a firm's existence.
\end{abstract}

Key words: Overconfidence; Firm Survival; Hazard Rates; Small Businesses; Kauffman Firm Survey

\section{Introduction}

Not all are created equal in the formation and survival of businesses. In particular, certain characteristics of entrepreneurs and their firms affect its eventual survival and success. One interesting characteristic that has received relatively little attention in the literature is overconfidence. While some authors have shown that overconfidence is positively related with firm survival (Baek and Neymotin 2018), the present analysis is the first to explore the mediating effects of minority status within entrepreneurship. In particular, we explore the roles of gender, and to a lesser extent of race, in working jointly with overconfidence to affect the survival rates of firms.

We employ Malmendier and Tate's (2005) concept of overconfidence to construct our measure. That is, we use the label "overconfident" when the head of the firm-or in our 
case, the owner-believes that the firm is performing better than outside firm evaluations would indicate. We employ the average Return on Assets (ROA) in the first few years of a firm's life and compare that to the same value for the industry that it occupies as a measure of its outside 'evaluation.' If a firm owner believes that her firm possesses a "competitive advantage" despite having a significantly worse ROA performance relative to its industry, we label this firm owner as overconfident in the same sense as in Malmendier and Tate (2005).

The firms in question-smaller, private US firms-were founded in the same year (2004) and are, therefore, all at the same point in their life cycle of production. We find that, while overconfidence is beneficial for the survival of all firms, it is particularly beneficial for the survival of female-led firms. This result stands in stark contrast to previous work in the literature that found that female-led firms have inferior outcomes, and that women more generally tend to be less cut-throat when faced with the prospect of competition (Dwyer et al. 2002; Gneezy et al. 2009). In our case, the willingness of female entrepreneurs to continue to compete given negative signals of their firm's value stands in opposition to a literature that generally predicts that they should instead choose to exit given signs of heavy competition. It is overconfidence in women, more so than in men, that appears to spur the firm on to continued survival.

While it is possible that women and men differentially use overconfidence to select into becoming entrepreneurs, this empirical consideration is left to others. Overconfidence may cause women in particular to "enter" into small firm entrepreneurial ventures, so that a higher survival rate on the part of their firms would simply reflect the differential vetting process for those of a minority status within entrepreneurship. While this does have important larger implications for early education and sociocultural retraining, given current social norms, the present finding remains quite important. Our findings and their associated implications should be understood in light of the current policy climate faced by small entrepreneurial ventures.

\section{Literature Review}

It has been well established in the literature that men show more competitive traits compared with women (Croson and Gneezy, 2009). The ultimate reason given for this difference in competitiveness by gender is typically the structure and implicit conditioning provided through society and its norms (Gneezy et al., 2009). Examining gender differentiation after this societal conditioning has taken place, however, there are a number of possible channels whereby competitiveness may be differentiated by gender. One very real difference could be the clearly observable variation in risk aversion displayed by gender throughout most environments and tasks (Croson and Gneezy, 2009). In recent years, authors have begun to veer away from their unanimous insistence that women are more risk-averse than men and have begun to find instances where levels of competition in women approach or even exceed those of men.

More specifically, Finucane et al. (2000) showed that previously displayed gender differences in competitiveness might only apply to the dominant ethnic group in their analysis. They found that only white men, as compared with white women, displayed a 
gender difference, however, this was absent from comparisons of all other ethnic groups in the analysis. The authors appropriately described the difference in competitiveness as the "white male effect."

The specific task under analysis may also affect the degree of competition that men and women are willing to display. In their 2004 study, Gneezy and Rustichini found that, while more men choose a competitive environment than do women, this gender gap in competitiveness is moderated by whether the task is generally favored by men or by women. For the experimental tasks that are usually male-oriented (such as shooting baskets), the gender gap is quite large, with a great deal more men choosing to be competitive. For the tasks women usually dominate (like solving anagrams), this gap is significantly smaller.

Another approach is to consider self-confidence and its variation by gender. Holding all else equal, if there is a lower average level of self-confidence for women, even with the same levels of relative risk aversion, it is possible that women will display lower levels of competitiveness. That is to say, if women's priors regarding the outcomes of their decisions are different because of their self-confidence levels, this alone could affect their ultimate choices. Estes and Hosseini (1988) showed that women were indeed less confident than men when making hypothetical investment decisions. Niederle and Vesterlund (2007) found, in a comparison by gender for math problem solving tasks, that sampled men were substantially more overconfident about their relative performance than were the women in the experiment. Finally, Koellinger et al. (2008) examined more than 40,000 observations in the 2001 Global Entrepreneurship Monitor (GEM) survey and found that the women's average levels of optimism and self-confidence were lower than the averages for men in the sample. In contrast, fear of failure for individuals in the sample was higher on average for women than for men.

In the context of the current analysis, however, it is important to understand how gender relates with the outcomes of entrepreneurship. The previously enumerated discussion establishes a framework whereby differences in competitiveness, initially thought to unanimously favor men, may be less unidirectional. In addition to whether the tasks favor men or women more generally, the pathway of greatest interest is selfconfidence. It appears that these differences in self-confidence by gender may play a key role in the decision to become an entrepreneur, and the subsequent outcomes of a firm's decision-making process.

To be more precise, the first step in the process of entrepreneurial outcomes would be whether gender affects the decision to become an entrepreneur. When asked to examine their plans for the future, female students had lower perceived feasibility and perceived desirability, and were less willing to start their own businesses than were males (Dabic et al. 2012). Similarly, among 216 male and 155 female undergraduate business administration students, men were shown to have a stronger career preference for entrepreneurship (Scherer et al. 1990).

Implicating confidence levels, Neymotin (2018) showed that gender affects the propensity to become a business major in college, with higher levels of overconfidence affecting the likelihood that women, but not men, will choose to major in business. Clearly 
then, gender and its relationship to self-confidence can be implicated from the very earliest stages of the entrepreneurial decision-making process.

After leaving college, individuals must then make the decision as to whether or not they will actually start their own business. This too appears to hinge on self-confidence levels, since entrepreneurs have greater degrees of overconfidence than the general population (Koellinger et al. 2006). Koellinger et al. (2008) examined the pathway to entrepreneurship and they found a relationship between confidence levels and entrepreneurship, with the added dimensionality of gender. Specifically, these authors found that women have a significantly lower propensity to start their own businesses, which is highly correlated with their lower average levels of optimism and self-confidence, as well as higher measured fear of failure. In keeping with the previous results in Neymotin (2018), however, these authors also found that women who are more self-confident and undeterred by failure have a greater probability to start their own business than do men with otherwise similar characteristics.

Similarly, Niederle and Vesterlund (2007) found that men's beliefs regarding their own relative performance will help predict their entry decisions into a competitive environment. From the reverse perspective, a lack of self-confidence appears to be a key barrier for women in choosing to enter the arena of business ownership (Fielden et al., 2003). Unfortunately, as Kirkwood (2009) documents, it may be the case that female entrepreneurs exhibit a lack of self-confidence in their own entrepreneurial abilities, as compared to their male counterparts.

Because of this self-selection by confidence levels into entrepreneurship, it is possible that the actual competitiveness of male and female entrepreneurs will not differ that greatly. In other words, self-selection may explain the attenuation of gender differences in overconfidence levels among entrepreneurs. Evidence to this effect has come from studies showing that women who are more competitive choose to be in competitive environments (Johnson and Powell 1994; Atkinson et al. 2003; Nekby et al. 2008). At the nuts-and-bolts level, if the women who were unwilling to compete were selected out at earlier stages of the process - including choosing a business major, starting a business, surviving the first few years of ownership - then it is entirely possible that documented levels of competitiveness between the entrepreneurs will no longer vary by gender. This hypothesis is supported by Ahmed's (2011) study examining the television show "Come Dine with Me." The author found that, due to the high levels of self-selection into being willing to be a chef and compete on the show, there were no observable differences in competitiveness by gender.

A number of other studies appear to mirror this result. Iqbal et al. (2006) examined risk aversion among executives at S\&P-indexed firms and found that male executives actually show a greater degree of risk aversion than the female executives, with the men engaging in higher diversification-related stock sales. Similarly, Ofek and Yermack (2000) showed that managers with a large investment in the firm's stock will begin to sell their shares when new stock options are awarded to them, where selling stocks is seen as an effort to diversify and hence an indication of risk averseness. Additionally, Johnson and Powell (1994) reported that males and females in the managerial sub-population who have undergone formal management education display similar risk propensities and make 
decisions of equal quality. Taken together, it appears that if there is any difference in management decision-making based on competitiveness or risk preferences, then these are weeded out prior to the point at which trained managers are asked to make decisions that affect their firms. Master and Meier (1988) also reported similar behaviors between males and females with participants who owned or managed a small business, and Birley (1989) found similar results among a sample of entrepreneurs.

Regarding investing and accounting, Atkinson et al. (2003) found that among fixed-income mutual fund managers, males and females do not manage funds differently in terms of performance, risk, or other fund characteristics. Hardies et al. (2013) found that female auditors are just as overconfident as their male counterparts, although admittedly not as risk-loving. Finally, Bliss and Potter (2002) even found that female mutual fund managers hold portfolios with marginally higher risk than their male counterparts.

Gender differences among established professionals in other fields are usually insignificant or imperceptible, and these women do not seem to behave in a more riskaverse or less competitive fashion. In Greek data, Tsaoussi (2008) reported no gender gap in risk aversion or negotiating behavior among attorneys, arguing that gender differences are unlikely to persist in groups of employees within a distinct professional culture. The authors used "distinct professional culture" in a similar fashion as the argument made here regarding the process of self-selection into a profession. Nevertheless, some studies do show a certain amount of variation in results, with Rozier and Thompson (1998) finding a self-confidence continuum within a sample of women health professionals.

Finally, the findings in the present analysis are perhaps most similar to those in the study by Nekby et al. (2008), in which female marathon runners were seven percentage points more likely to be overconfident relative to their male counterparts. In that study, the likelihood of being overconfident turned out to be lowest for the groups of individuals who had the slowest start time for their race. Overconfident runners improved their time by 2.27 minutes on average relative to the rest of their competitors. This finding is quite similar to the results in the present analysis, showing that overconfidence can have a positive impact on performance, and that women in the sample are actually more likely to be overconfident than are their male peers.

\section{Data and Methodology}

We employ the restricted-access Kauffman Firm Survey (KFS) micro-dataset, housed at the National Opinion Research Center (NORC) in Chicago. The KFS tracks the form and function of US-based, small, privately-held startup ventures. The KFS panel dataset is composed of 4,928 new businesses that began operating in the year 2004. The firms were followed annually until 2014. Because the survey designers intended to elicit a nationally representative dataset of entrepreneurial ventures that all began in the same year, the KFS is frequently considered one of the largest, and most current vetted surveys focusing on the behaviors of small private startups.

For the present study of small, privately-held startup firms, most of the measures focusing on larger firm issues are either irrelevant or unobservable (Hirshleifer et al. 2012; Hribar and Yang 2015). In particular, drawing on comparisons with the existing literature, 
(1) Plans for stock options are either nonexistent or unobservable for our sample of small firms; (2) KFS firms are not publicly traded, so that it is impossible to determine whether continuing to manage and run a company, in the form of holding company equity, is due to firm owner overconfidence or due to a lack of liquidity; (3) Small private startup firms rarely receive press coverage, so that we cannot employ this as a measure of potential firm owner overconfidence.

The structure we employ here instead to categorize a firm owner as overconfident is in keeping with that found in Baek and Neymotin (2018) using a measure of overoptimism. Specifically, a firm owner is classified as "overconfident" if (1) she believes that her firm has a competitive advantage, and (2) the firm underperformed relative to its industry. We categorize a firm as underperforming when its average ROA in its first years (2004-2007) is below the industry's median ROA during that time-period. We categorize a KFS firm owner as believing her firm has a competitive advantage based on whether she answered yes to the following survey question: Businesses often have to compete with other businesses. A competitive advantage is something unique or distinctive that a business provides and that gives it an advantage compared to competitors. In calendar year YYYY, did [NAME BUSINESS] have a competitive advantage over its competitors?

All firms surviving until 2007 or later were asked this overconfidence question. We examined these firms to see whether they failed in any of the years 2004-2012. If a firm was in operation in any given year and answered that they had not failed, then we considered them to have survived in that year. Due to item non-response, we also assumed that when a firm was in operation and answered that they had survived in the prior year and in the subsequent year, we also assumed that they had survived during the intermediate year(s).

We employed several firm characteristics as additional control factors in the analysis. The KFS assigns each firm a six-digit North American Industry Classification System (NAICS) code. We converted these codes into their corresponding Standard Industrial Classification (SIC) codes. This led to the formation of twenty-three distinct industry binary variables. For the regression analysis, these SIC codes were used as fixedeffects. The other firm characteristic that we considered essential for the regression analysis was the total initial firm assets at the time of its formation, used as a proxy for firm size. We considered this an essential addition since return on assets is likely to be better for larger firms.

In keeping with other authors in the literature (Fairlie and Robb 2007; Baek and Neymotin 2016; 2018), we also focused on the essential entrepreneurial characteristics of the primary owner of the firm, that is the owner with the largest share in the business. We employed gender, race, age, work experience, and education of the primary owner as control factors in our analysis. Age was included due to its likely relationship with experience and the possibly enhanced decision-making abilities of older adults. We also determined the industry-specific work experience of the owner from the KFS question asking: How many years of work experience (have/has) OWNER had in this industry-the one in which NAME BUSINESS competes?

Given our interest in small, new-firm failure or survival, we chose to follow the survival-techniques now being employed in the literature (Esteve-Perez et al. 2007; Baek 
and Neymotin 2018). In the present analysis, we used a maximum likelihood hazard model with a Weibull distribution as our method of determining survival times. We further assumed that a firm could fail in any year between 2004 and 2012, thus the measure of firm accomplishment we examined was its ability to continue in operation at the same time many of its peers were failing and liquidating their operations.

The hazard model is commonly used to evaluate survival processes in economics, and the Weibull distribution was chosen as the parametrization due to the generality of its functional form (Cameron and Trivedi 2010). In such survival models, "1- the coefficient on the regressor" can be interpreted as the marginal increase in the chance of survival due to that variable being introduced. As an example, a coefficient of 0.8 for work experience would imply that a one unit increase in work experience would decrease survival rates by $20 \%$.

It would be very difficult to model this same functional relationship with an alternative structure such as an OLS model. Nevertheless, if one chose to use OLS, with years survived as the left-hand-side variable, then the coefficient on work experience could be interpreted as the marginal effect of a one unit increase on the total years survived. Clearly the interpretation is different in the hazard model, and distributional assumptions would follow a typical OLS format. If instead one employed a probit or logit format, then a priori restrictions would need to be made on the binary decision of what it meant to "succeed" (1) or to "fail" (0) to interpret the marginal effect of the coefficient in an even somewhat similar fashion as in the hazard function.

We further assumed that the likelihood of failing would increase or decrease depending on any of the preceding firm or owner characteristics. The present analysis focused on the characteristics of overconfidence, gender, and race. The maximum number of years a firm could have survived was eight, meaning that the firm began in 2004 and was still in operation in 2012. In contrast, a failure in year " 0 " would occur if the firm sampled in the year 2004 had already exited the industry during 2004. Due to the sampling frame, however, all failures occurred in year 1 or later.

\section{Results}

Table 1 displays the count and percentage for overconfidence in the data sample. Results are shown both for the full sample as well as stratified by gender and by race, with the four largest ethnic categories displayed. Some results for Asian men and women are suppressed due to confidentiality restrictions. We focused on these four races due to disclosure concerns in the confidential data, and we felt comfortable making this simplification, since results in the regression analysis were essentially unchanged when we included or dropped the additional smaller ethnic/racial groups in the study.

There are more male than female entrepreneurs in the dataset, with three-fourths being male. Most individuals are also from the "white" racial category. In terms of overconfidence, however, more women than men are overconfident, with $22 \%$ of women and just $19 \%$ of men being overconfident-significantly different at the $1 \%$ level. While racial breakdowns are generally similar, Black individuals are less overconfident, while Asian and Hispanic individuals are more overconfident than are their white counterparts, 
although only the Hispanic percentage is significantly different from the white counterpart at conventional levels.

TABLE 1: Overconfidence by Race and Gender

\begin{tabular}{|c|c|c|c|c|}
\hline & & Counts & Overconf. & $\%$ \\
\hline & Men & 8497 & 1624 & $19.1 \%$ \\
\hline & Women & 2822 & 622 & $22.0 \%$ \\
\hline & White & 9291 & 1839 & $19.8 \%$ \\
\hline & Black & 747 & 124 & $16.6 \%$ \\
\hline & Asian & 424 & 96 & $22.6 \%$ \\
\hline & Hispanic & 538 & 121 & $22.5 \%{ }^{*}$ \\
\hline \multirow[t]{4}{*}{ Men } & White & 7022 & 1334 & $19.0 \%$ \\
\hline & Black & 484 & 87 & $18.0 \%$ \\
\hline & Asian & -- & -- & $24.5 \%{ }^{*}$ \\
\hline & Hispanic & 427 & 78 & $18.3 \%$ \\
\hline \multirow[t]{4}{*}{ Women } & White & 2069 & 505 & $24.4 \%$ \\
\hline & Black & 263 & 37 & $14.1 \%{ }^{*}$ \\
\hline & Asian & -- & -- & $17.0 \%{ }^{*}$ \\
\hline & Hispanic & 111 & 43 & $38.7 \%$ * \\
\hline
\end{tabular}

Source: Own calculations using 2004-2012 data from the Kauffman Firm Survey.

* indicates significance at the $5 \%$ level, and ** indicates significance at the $1 \%$ level. Gender comparisons use male as the baseline. Racial (within-category) comparisons use white as the Baseline.

The next portion of table 1 determines how much of the variation in overconfidence can be explained by male versus female differences by race. Black and Asian women are much less overconfident than are white women, while Hispanic women are significantly more overconfident than white women. Results for Black men are similar to those for Black women, however, Asian and Hispanic men do look somewhat different than Asian and Hispanic women. Asian men are actually more overconfident than are white men, while Hispanic men are less overconfident than white men, in contrast with the results for Asian and Hispanic women. These results are also displayed in Figure 1, where it becomes immediately apparent that the lowest rates of overconfidence belong to Black women, and the highest to Hispanic women.

It is also the case that the racial differences relative to the white Female baseline are more significant (for Hispanic women, Asian women, and for Black women), while racial differences relative to the white male baseline are only significant for Asian men. This also points to the importance of determining how overconfidence affects women differently from men. 


\section{FIGURE 1}

\section{Overconfidence by Race and Gender}

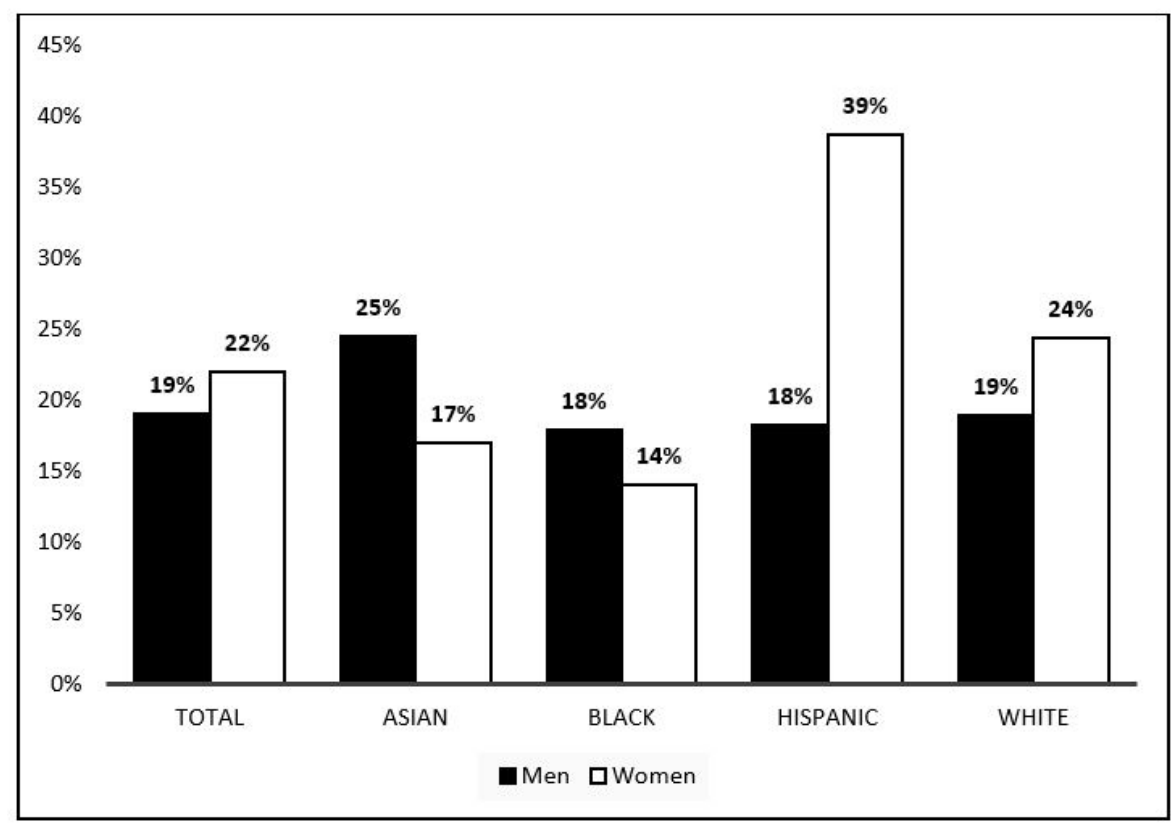

Source: Own calculations using 2004-2012 data from the Kauffman Firm Survey.

Taken together, it appears that gender as well as race play significant roles in mediating the effects of entrepreneurial overconfidence. While useful as a baseline estimate for overconfidence levels, we next consider the even more important question of how overconfidence plays a part in the outcome of firms, and, on their survival. To this end, table 2 shows the effects of overconfidence, race, and gender on the likelihood that a firm will stay in business over the period in question. Additional control variables included in the analysis but not displayed in the table are the education, age, and previous work experience of the entrepreneur, the total initial assets for the firm, and the industry classification of the firm.

The first column of the analysis represents a regression for the full population without any gender controls. The second column replicates the first column; however, additional controls are included for both gender and the interaction between gender and overconfidence. Finally, columns three and four split the regression to include observations from only men and only women respectively. These last regressions are included to allow for a more flexible functional form in gender's interaction with the other variables in the analysis.

Our survival model is a Weibull form hazard regression, so that the coefficient on the variable of interest can be subtracted from "1" to determine exactly how much more or less likely the inclusion of that variable makes it for the firm to survive longer. For example, overconfidence has a coefficient of 0.728 in column [1]. This translates into a 1$0.728=0.272$, or a $27.2 \%$ higher likelihood of survival for overconfident firms. It is also 
apparent from the column [3] regression that male-led firms with an overconfident entrepreneur are $20.6 \%$ more likely to survive, while there is a much larger boost from overconfidence to the female-led firms in the column [4] regression. These female-led firms appear to have a $63.1 \%$ higher chance of survival simply due to the overconfidence of the entrepreneur, with a Chi-squared coefficient of difference between these two regressions showing a $p$ value of 0.001 , that is, the effects for males are different than for females. Clearly then, being overconfident is beneficial for firm survival, and it is particularly beneficial for the survival of female-led firms. The column [2] regression further confirms these results, since for this full population regression with gendered effects included, being a female entrepreneur generally leads to a $1-1.289=-28.9 \%$ drop in the likelihood of survival, while being an overconfident woman leads to a $1-0.674=32.6 \%$ increase in the likelihood of survival. It hurts to be a female entrepreneur for survival rates, but it helps to be an overconfident female entrepreneur. Even if there is differential selection by gender into being an entrepreneur based on overconfidence, our results make apparent that these effects of overconfidence continue to play a role even at this later stage of firm survival analysis.

\section{TABLE 2: Predictors of Survival}

\begin{tabular}{|c|c|c|c|c|}
\hline & \multicolumn{4}{|c|}{ Hazard Ratio } \\
\hline & $\begin{array}{l}{[1]} \\
\text { Total }\end{array}$ & $\begin{array}{l}\text { [2] } \\
\text { Total(Gender) }\end{array}$ & $\begin{array}{l}{[3]} \\
\text { Male }\end{array}$ & $\begin{array}{l}{[4]} \\
\text { Female }\end{array}$ \\
\hline \multirow[t]{2}{*}{ Overconf. } & 0.728 & 0.796 & 0.794 & 0.369 \\
\hline & {$[-5.59]^{* *}$} & {$[-3.52]^{* * *}$} & {$[-3.53]^{* *}$} & {$[-6.77]^{\star \star}$} \\
\hline \multirow[t]{2}{*}{ Black } & 0.664 & 0.668 & 0.598 & 1.065 \\
\hline & {$[-3.74]^{* *}$} & {$[-3.69]^{\star * *}$} & {$[-3.82]^{\star *}$} & {$[0.31]$} \\
\hline \multirow[t]{2}{*}{ Asian } & 0.905 & 0.884 & 0.847 & 1.036 \\
\hline & {$[-0.67]$} & {$[-0.82]$} & {$[-0.89]$} & {$[0.14]$} \\
\hline \multirow[t]{2}{*}{ Hispanic } & 0.728 & 0.748 & 0.68 & 1.354 \\
\hline & {$[-2.61]^{\star *}$} & {$[-2.39]^{* *}$} & {$[-2.82]^{\star *}$} & [1.02] \\
\hline \multirow[t]{2}{*}{ Gender } & - & 1.289 & - & - \\
\hline & - & {$[3.49]^{\star * *}$} & - & - \\
\hline \multirow[t]{2}{*}{ Gender* OverConf. } & - & 0.674 & - & - \\
\hline & - & {$[-3.07]^{\star * *}$} & - & - \\
\hline $\mathbf{N}$ & 1712 & 1712 & 1307 & 405 \\
\hline
\end{tabular}

Source: Own calculations using 2004-2012 data from the Kauffman Firm Survey.

Coefficients in the Hazard model are displayed with t-statistics underneath in brackets. * indicates significance at the $5 \%$ level, and ${ }^{* *}$ indicates significance at the $1 \%$ level. Additional controls included in the regression but not displayed here are work experience, age, education, total firm assets, and SIC industry dummy variables.

The case for race is slightly less clear than the one for gender. While Black- and Hispanic-led firms may benefit from firm owner overconfidence (33.6\% and $27.2 \%$ for the full population regression [2]), and particularly for men $(40.2 \%$ and $32 \%$ for the male 
regression [3]), there does not appear to be a statistically significant effect of race on the survival rates of female-entrepreneur led firms. It is also true that Asian entrepreneurs do not appear to have a significantly different survival rate than the baseline group in any of the four regressions.

As for the control characteristics, we found that age is significant, but with a generally minor impact on firm survival (results not shown). While work experience and total assets were also of minor importance, they did not reach conventional levels of significance. Education only appeared to be important when moving from very low education to just slightly higher levels of education. The only noticeable differences between these regressions was that significance was further reduced for the column 4 female-only regressions.

\section{Conclusion}

In using the KFS, we have restricted ourselves to a large and well-vetted dataset regarding small-firm entrepreneurs. We have found that female entrepreneurs are more overconfident than male entrepreneurs in this data. This surprising result is partially explainable by selection into leading a business by more overconfident women in the first place, the later differential impact of this overconfidence on firm survival is even more striking. Specifically, firms led by overconfident female entrepreneurs benefit more in terms of firm survival from the overconfidence than do firms led by overconfident male entrepreneurs. In contrast to some findings in the literature that female personality characteristics may serve to harm firm outcomes (Kirkwood 2009), we find that female overconfidence serves to help their firms.

It is also true that overconfidence is sometimes viewed in a negative light, and that women are often seen as less confident in other parts of the literature (Croson and Gneezy 2009). Nevertheless, we understand our results in light of the fact that entrepreneurs are unlike larger firms due to their extremely high failure rates and the personal sacrifices required to ensure firm survival. Consequently, if a (small) firm owner is slightly "blind" to reality, it is possible that this lack of realism will allow her to persevere in the face of difficulty. This may occur in situations where a more realistic or a less optimistic individual would have already chosen to exit. In the words of Henry Ford: "Whether you think you can, or you think you can't...you're right."

Whether the business profits from the owner's decision not to liquidate is an entirely different matter and outside the context of this analysis. We ignore it here, since the first few years of a firm's existence are most important not in generating profits but simply for the fact of the firm having survived them. If they do not accrue unsurmountable debts, surviving firms generally have a more favorable outlook than those that shut down earlier on. Specifically, staying in business allows for the possibility of later growing the firm.

It is also true that our firms, in addition to having started their operations in the same year, were also all started at the same point in the business cycle. However, not all sectors were equally impacted by the economic downturn of 2008 . If race or gender 
impacts the sectoral choice of an entrepreneur, then this may play a part in affecting our results and is noted for future research.

The present analysis has taken a first step in exploring the very under-researched area of entrepreneurial characteristics, determining how these characteristics vary by gender and by minority status, and examining how these differences translate into differences in firm outcomes. Finding that overconfidence helps firms to survive, and that it helps women and some minorities more than it helps the majority group, may shed some much-needed light on methods and reasons for encouraging under-represented groups in male and white-dominated business operations.

Simply owning a business is not enough to encourage these entrepreneurs to persevere. A feeling that one's business is as good as the competition, perhaps even without justification, allows these women and minority owners to stick it out for the very difficult first years of a firm's life cycle. While an intervention to increase self-esteem may or may not be beneficial, confidence is clearly a part of the picture in understanding why some businesses succeed and others fail. Given the current context of small businesses often struggling to survive, and the changes in regulations and restrictions in the last decade regarding small business operations, understanding the entrepreneurial mindset is a key part in helping her succeed.

\section{References:}

Ahmed, A.M. (2011), Women are not always less competitive than men: Evidence from Come Dine with Me, Applied Economics Letters, Vol. 18, no. 12, pp. 1099-1101.

Atkinson, S.M., Baird, S.B., Frye, M.B. (2003), Do female mutual fund managers manage differently? Journal of Financial Research, Vol. 26, pp. 1-18.

Baek, H.Y., Neymotin, F. (2018), Entrepreneurial overconfidence and firm survival: An analysis using the Kauffman firm survey, Applied Economics Letters, Vol. 25, no. 16, pp. 1175-1178.

Baek, H.Y., Neymotin, F. (2016), International involvement and production efficiency among startup firms, Global Economic Review, Vol. 45, no. 1, pp. 42-62.

Birley, S. (1989), Female entrepreneurs: Are they really any different? Journal of Small Business Management, Vol. 27, pp. 32-37.

Bliss, R.T., Potter, M.E. (2002), Mutual fund managers: Does gender matter? Journal of Business and Economic Studies, Vol. 8, pp. 1-15.

Cameron, A.C., Trivedi, P.K. (2010), Microeconomics Using Stata, Taylor and Francis, New York.

Croson, R., Gneezy, U. (2009), Gender differences in preferences, Journal of Economic Literature, Vol. 47, pp. 448-74.

Dabic, M., Daim, T., Bayraktaroglu, E., Novak, I., Basic, M. (2012), Exploring gender differences in attitudes of university students towards entrepreneurship: An international survey, International Journal of Gender and Entrepreneurship, Vol. 4, no. 3, pp. 316-336.

Dwyer, P.D., Gilkeson, J.H., List, J.A. (2002), Gender differences in revealed risk taking: evidence from mutual fund investors, Economics Letters, Vol. 76, pp. 145-58.

Estes, R., Hosseini, J. (1988), The Gender Gap on Wall Street: An Empirical Analysis of Confidence in Investment Decision Making, The Journal of Psychology, Vol. 122, no. 6, pp. 577-590.

Esteve-Perez, S., Manez-Castillejo, J.A., Rochina-Barrachina, M.E., Sanchis-Llopis, J.A. (2007), A survival analysis of manufacturing firms in export markets, Unpublished Paper.

Fairlie, R.W., Robb, A.M. (2007), Families, Human Capital, and Small Business: Evidence from the Characteristics of Business Owners Survey, ILR Review, Vol. 60, no. 2, pp. 225-245. 
Fielden, S.L., Davidson, M.J., Dawe, A.J., Makin, P.J. (2003), Factors inhibiting the economic growth of female owned small businesses in North West England, Journal of Small Business and Enterprise Development, Vol. 10, no. 2, pp. 152-166.

Finucane, M.L., Slovic, P., Mertz, C.K., Flynn, J., Satterfield, T.A. (2000), Gender, race, and perceived risk: The 'White Male' effect, Health, Risk and Society, Vol. 2, no. 2, pp. 159-172.

Gneezy, U., Leonard, K.L., List, J.A. (2009), Gender differences in competition: evidence from a matrilineal and a patriarchal society, Econometrica, Vol. 77, pp. 1637-64.

Gneezy, U., Rustichini, A. (2004), Executives versus teachers, Unpublished Manuscript.

Hardies, K., Breesch, D., Branson, J. (2013), Gender differences in overconfidence and risk taking: Do self-selection and socialization matter? Economics Letters, Vol. 118, pp. 442-444.

Hirshleifer, D., Low, A., Teoh, S.H. (2012), Are overconfident CEOs better innovators? Journal of Finance, Vol. 4, pp. 1457-1498.

Hribar, P., Yang, H. (2015), CEO overconfidence and management forecasting, Contemporary Accounting Research, Vol. 33, no. 1, pp. 204-227.

Iqbal, Z., O, S., Baek, H.Y. (2006), Are female executives more risk-averse than male executives? Atlantic Economic Journal, Vol. 34, pp. 63-74.

Johnson, J.E.V., Powell, P.L. (1994), Decision making, risk and gender: Are managers different? British Journal of Management, Vol. 5, pp. 123-138.

Kauffman Foundation, 2004-2012, Kauffman Firm Survey, documentation available online at https://www.kauffman.org/microsites/kfs/data-files Last Accessed August 7, 2018

Kirkwood, J. (2009), Is a lack of self-confidence hindering women entrepreneurs? International Journal of Gender and Entrepreneurship, Vol. 1, no. 2, pp. 118-133.

Koellinger, P., Minniti, M., Schade, C. (2006), 'I think I can, I think I can': overconfidence and entrepreneurial behavior, Journal of Economic Psychology, Vol. 28, pp. 502-527.

Koellinger, P., Minniti, M., Schade, C. (2008), Seeing the world with different eyes: gender differences in perceptions and the propensity to start a business, Tinbergen Institute Discussion Paper 035/3.

Malmendier, U., Tate, G. (2005), CEO Overconfidence and Corporate Investment, The Journal of Finance, Vol. 60, no. 6, pp. 2661-2700.

Master, R., Meier, R. (1988), Sex differences and risk-taking propensity of entrepreneurs, Journal of Small Business Management, Vol. 26, pp. 31-35.

Nekby, L., Thoursie, P.S., Vahtrik, L. (2008), Gender and self-selection into a competitive environment: are women more overconfident than men? Economics Letters, Vol. 100, pp. 405-407.

Neymotin, F. (2018), Educational Overconfidence and the Path to Business, The Empirical Economics Letters, Vol. 17, no. 7, pp. 1-10.

Niederle, M., Vesterlund, L. (2007). Do women shy away from competition? Do men compete too much? Quarterly Journal of Economics, Vol. 122, no. 3, pp. 1067-1101.

Ofek, E., Yermack, D. (2000), Taking stock: Equity-based compensation and the evolution of managerial ownership, Journal of Finance, Vol. 55, pp. 1367-1384.

Rozier, C.K., Thompson, M. (1998), Female entrepreneurs in a female-dominated health profession: an exploratory study, Journal of Developmental Entrepreneurship, Vol. 3, no. 2, pp. 149163.

Scherer, R.F., Brodzinski, J.D., Wiebe, F.A. (1990), Entrepreneur career selection and gender: a socialization approach, Journal of Small Business Management, Vol. 28, no. 2, pp. 37-42.

Tsaoussi, A. (2008). Female Lawyers as Pragmatic Problem Solvers: Negotiation and Gender Roles in Greek Legal Practice. The Theory and Practice of Representative Negotiation, Trevor Farrow, Colleen Hanycz, Fred Zemans, eds., pp. 198-210, Emond Montgomery Publications, Toronto, 2008. 